\title{
Purkinje Cells Are More Vulnerable to the Specific Depletion of Cathepsin D Than to That of Atg7
}

Masato Koike, ${ }^{\star}$ Masahiro Shibata, ${ }^{\dagger}$ Takehiko Sunabori, ${ }^{\star \ddagger}$ Junji Yamaguchi, ${ }^{\ddagger}$ Kenji Sakimura, ${ }^{\S}$ Masaaki Komatsu, ${ }^{\top}$ Keiji Tanaka, and Yasuo Uchiyama

From the Departments of Cell Biology and Neuroscience* and Cellular and Molecular Neuropathology, ${ }^{\ddagger}$ Juntendo University Graduate School of Medicine, Bunkyo-ku, Tokyo; the Department of Morphological Sciences, ${ }^{\dagger}$ Kagoshima University Graduate School of Medical and Dental Sciences, Kagoshima; the Department of Cellular Neurobiology, ${ }^{\S}$ Brain Research Institute, Niigata University, Niigata; the Department of Molecular Genetics, ${ }^{\boldsymbol{\top}}$ Niigata University Graduate School of Medical and Dental Sciences, Niigata; and the Laboratory of Protein Metabolism," Tokyo Metropolitan Institute of Medical Science, Setagaya-Ku, Tokyo, Japan

\author{
Accepted for publication \\ February 27, 2017. \\ Address correspondence to \\ Yasuo Uchiyama, M.D., Ph.D., \\ Department of Cellular and \\ Molecular Neuropathology, \\ Juntendo University \\ Graduate School of \\ Medicine, 2-1-1 Hongo, \\ Bunkyo-ku, Tokyo 113-8421, \\ Japan. E-mail: y-uchi@ \\ juntendo.ac.jp.
}

\begin{abstract}
Neurologic phenotypes of cathepsin D (CTSD)-deficient mice, a murine model of neuronal ceroid lipofuscinoses, indicate the importance of CTSD for the maintenance of metabolism in central nervous system neurons. To further understand the role of CTSD in central nervous system neurons, we generated mice with a CTSD deficiency specifically in the Purkinje cells (PCS) (CTSD Flox/Flox;GRID2-Cre) and compared their phenotypes with those of PC-selective Atg7-deficient (Atg $7^{\text {Flox/Flox }}$;GRID2-Cre) mice. In both strains of mice, PCs underwent degeneration, but the CTSD-deficient PCS disappeared more rapidly than their Atg7-deficient counterparts. When CTSD-deficient PCs died, the neuronal cell bodies became shrunken, filled with autophagosomes and autolysosomes, and had nuclei with dispersed small chromatin fragments. The dying Atg7-deficient PCs also showed similar ultrastructures, indicating that the neuronal cell death of CTSD- and Atg7-deficient PCs was distinct from apoptosis. Immunohistochemical observations showed the formation of calbindin-positive axonal spheroids and the swelling of vesicular GABA transporter-positive presynaptic terminals that were more pronounced in Atg7-deficient PCs than in CTSD-deficient PCs. An accumulation of tubular vesicles may have derived from the smooth endoplasmic reticulum; nascent autophagosome-like structures with double membranes was a common feature in the swollen axons of these PCs. These results suggested that PCs were more vulnerable to CTSD deficiency in lysosomes than to autophagy impairment, and this vulnerability does not depend on the severity of axonal swelling. (Am J Pathol 2017, 187: 1586-1600; http://dx.doi.org/10.1016/j.ajpath.2017.02.020)
\end{abstract}

Lysosomes are multifunctional membrane-bound acidic organelles that contain various acid hydrolases that degrade excess, old, and unneeded intracellular and extracellular materials, including cytoplasmic organelles, into biologically active monomers. ${ }^{1,2}$ We previously showed that the central nervous system neurons of mouse brains deficient in CTSD present a new form of lysosomal accumulation disease with a phenotype resembling neuronal ceroid lipofuscinosis (NCL). ${ }^{3-6}$ NCLs are the most common inherited neurodegenerative disorders in childhood and are categorized as a lysosomal storage disorder. ${ }^{7}$ Recently, $C T S D$ has proven to be the gene that is responsible for the most severe (congenital) type of NCL, currently denoted as CLN10 (Online Mendelian Inheritance in Man no. 116840). ${ }^{8-11}$
CTSD deficiency induces massive cell death in brain and retinal tissues, in which at least two types of cell death are distinguishable. First, there is typical apoptosis of

\footnotetext{
Supported by the Brain Mapping by Integrated Neurotechnologies for Disease Studies (Brain/MINDS) from Japan Agency for Medical Research and Development AMED (M.K.), Scientific Research on Innovative Areas grants 23111004 (Y.U.) and 26111519 and 15H01388 (M.K.), Scientific Research (B) grant-in-aid 23390041 (Y.U.), Scientific Research (C) grant-inaid 25460276 (M.K.), Challenging Exploratory Research grant-in-aid 25670099 (Y.U.), a grant-in-aid for the High-Tech Research Center Project for Private Universities, a matching fund subsidy (Y.U.), the Program for the Strategic Research Foundation at Private Universities (Y.U.), the Private University Research Branding Project (M.K.) from the Ministry of Education, Culture, Sports, Science and Technology of Japan, and the Nagao Takeshi Nanbyo Foundation (M.K.).

Disclosures: None declared.
} 
photoreceptor cells leading to retinal atrophy. Second, there is neuronal cell death in the thalamus and in the retinal inner nuclear layer that is mediated by nitric oxide derived from activated microglial cells. ${ }^{4,6}$ Moreover, a genetic study using CTSD and BAX double knockout (KO) mice has shown that cell death in the cerebral cortex and hippocampus cannot be prevented by additional $B A X$ deficiency, indicating that cell death in these regions is mediated in a caspase-independent manner. ${ }^{12}$ These studies indicate that vulnerability and types of neuronal cell death may be dependent on brain regions.

Because constitutive KO mice of CTSD $\left(C T S D^{-1-}\right.$ mice $)$ die at around postnatal day (P) $26 \pm 1,{ }^{3,13}$ it is difficult to determine the region dependency of neuronal cell vulnerability to $C T S D$ deficiency. Moreover, although activation of astrocytes and microglia is known to occur in a region-dependent manner in $C T S D^{-1-}$ brains, ${ }^{6,14}$ it remains unclear whether CTSD-deficient neurons undergo cell autonomous degeneration without the contribution of other glial cells. Therefore, to further explain region-specific neuronal damage and the cellautonomous degenerative process by CTSD deficiency, we generated conditional KO mice for $C T S D .^{15,16}$

According to a recent case report, ${ }^{9} \mathrm{CLN} 10$ is divided into two subtypes based on age at the onset of symptoms. Homozygous null or missense mutations of the human CTSD gene result in congenital CLN10 disease with microcephaly, ${ }^{8,10}$ and juvenile CLN10 disease is characterized by ataxia, retinitis pigmentosa, and cognitive decline. ${ }^{9,11}$ Therefore, to gain insight into the ataxic symptoms of CLN10 disease, we generated Purkinje cell (PC)-specific $C T S D$-deficient mice by crossing the $C T S D$ conditional $\mathrm{KO}$ mice with a $\mathrm{Cre}$-knockin strain, D2CreN, under the control of a GRID2 gene promoter. ${ }^{17}$ Moreover, because PCs are vulnerable to autophagy impairment due to conditional $\mathrm{KO}$ of $\operatorname{Atg} 7$ or $A \operatorname{tg} 5,{ }^{18,19}$ and because it is known that mutations in the human Atg5 gene reduce autophagy and lead to ataxia, ${ }^{20}$ we generated novel PC-selective Atg7-conditional KO mice by crossing the Atg7-floxed mice ${ }^{21}$ with D2CreN mice. Then, we compared the neurodegenerative processes in CTSD-deficient and Atg7-deficient PCs.

\section{Materials and Methods}

The procedures involving animal care and sample preparation were approved by the Animal Experimental Committee of Juntendo University Graduate School of Medicine (permit no. 250002) and were performed in accordance with the NIH's guidelines ${ }^{22}$ and the regulations and guidelines for the care and use of laboratory animals of Juntendo University Graduate School of Medicine.

\section{Generation of PC-Selective CTSD and Atg7 KO Mice}

A bacterial artificial chromosome clone (RP23-145I16) carrying the CTSD gene was purchased from the BACPAC Resource Center (Oakland, CA) and used in the generation of
$C T S D$-floxed $\left(C T S D^{\text {Flox/Flox }}\right)$ mice. ${ }^{15,16}$ A targeting vector was constructed by inserting loxP sites into intron- 1 and -2 of the $C T S D$ gene using Escherichia coli-based bacterial artificial chromosome recombination. A FRT-PGK-Neo-FRT cassette was introduced into intron-2, followed by a second loxP sequence (Supplemental Figure S1A). The targeting vector was linearized by PmeI digestion and electroporated into mouse v6.5 embryonic stem cells, ${ }^{23}$ and positive clones were selected by adding $150 \mathrm{mg} / \mathrm{mL}$ G418. Genomic DNA isolated from G418-resistant colonies was screened for homologous recombination using PCR and confirmed by Southern blot analyses. The PCR primers used for homologous recombination screening included 5'-GCTGCTAAAGCGCATGCTCCAGACTG-3' (forward) and 5'-CTCCTTCACAGTACTTGTTC$3^{\prime}$ (reverse). Genotyping of mice by PCR was performed using the following primers: $5^{\prime}$-TGTGGCTAGGGGCCAGGTTC- $3^{\prime}$ (forward) and $5^{\prime}$-TGCCCTGGTGAACCCAATCC- $3^{\prime}$ (reverse). Progeny containing the $C T S D^{\text {Flox(neo) }}$ allele were crossed with FLPe mice to delete the Neo cassette, and mice carrying the $C T S D^{\text {Flox/+ }}$ allele were obtained. These $C T S D^{\text {Flox/+ }}$ mice were further mated with one another to generate homozygous $\left(C T S D^{\text {Flox/Flox }}\right)$ mice (Supplemental Figure S1A).

Atg 7 floxed $\left(\operatorname{Atg} 7^{\text {Flox/Flox }}\right)^{21}$ and D2CreN (GRID2 $2^{+/ C r e}$ ) mice ${ }^{17}$ were transferred to the Institute of Experimental Animal Sciences, Juntendo University Graduate School of Medicine, and were housed in pathogen-free facilities. Genotyping of these strains of mice by PCR was performed using the following primers: $5^{\prime}$-TGGCTGCTACTTCTGCAATGATGT- $3^{\prime}$ (forward) and 5'-CAGGACAGAGACCATCAGCTCCAC- $3^{\prime}$ (reverse) for $A \operatorname{tg} 7^{\text {Flox/Flox }}$ mice and $5^{\prime}$-GGAGGCTGCCTCTGGCTGGCTGTGCTAGC- $3^{\prime}$ (forward), 5'-CTCTGGCAGCAGCCGGAGGCTCGAG-3' (reverse), and $5^{\prime}$-TGCTGTCACTTGGTCGTGGC-3' (reverse) for D2CreN mice.

To generate the PC-selective CTSD or Atg7 KO strain, either $C T S D^{\text {Flox/Flox }}$ or $A \operatorname{tg} 7^{\text {Flox/Flox }}$ were mated with D2CreN (GRID2 ${ }^{+/ C r e}$ ) mice. ${ }^{17}$ For each experiment, pairs (CTSD or Atg $7^{\text {Flox/Flox; }}$ GRID2 ${ }^{+/ C r e}$ and CTSD or Atg $7^{\text {Flox/Flox }}$; GRID2 ${ }^{+/+}$) were crossed to obtain control (CTSD or $A t g 7^{\text {Flox/Flox }}$ GRID2 ${ }^{+/+}$) and PC-selective CTSD or Atg7 KO $\left(C T S D\right.$ or $\left.A \operatorname{tg} 7^{\text {Flox/Flox }} ; \mathrm{GRID}^{+/ C r e}\right)$ mice. To generate conventional CTSD KO mice, CTSD Flox/Flox mice were mated with CAG-Cre mice that express $\mathrm{Cre}$ recombinase ubiquitously. ${ }^{24}$ The resulting $C T S D^{\text {Flox/Flox }} ; \mathrm{CAG}^{+/ C r e}$ mice were further crossed with C57BL/6N mice (Charles River Japan Inc., Tokyo, Japan) to obtain the heterozygous CTSD $\mathrm{KO}\left(C T S D^{+/-}\right)$mice, which were intercrossed to obtain homozygous CTSD KO $\left(C T S D^{-1-}\right)$ mice. Genotyping of $C T S D^{-1-}$ mice by PCR was performed using the following primers: $5^{\prime}$-TGTGGCTAGGGGCCAGGTTC- $3^{\prime}$ (forward) and 5'-GGAAGGTGAGACTAGTGG-3' (reverse).

\section{Antibodies}

Rabbit antibodies against rat cathepsin D (CTSD) and subunit $\mathrm{c}$ of mitochondrial ATP synthase were produced 
as previously described. ${ }^{5,14,25}$ Rabbit, guinea pig, goat, and mouse antibodies for microtubule-associated protein light chain 3A/B (LC3A/B; Cell Signaling Technology, Beverly, MA), active caspase-3 (Cell Signaling Technology), autophagy related 7 (Atg7; Cell Signaling Technology), ionized calcium-binding adapter molecule 1 (Iba1, also named allograft inflammatory factor 1; Wako Pure Chemical Industries, Osaka, Japan), sequestosome 1 (SQSTM1, also named p62; Wako Pure Chemical Industries), calbindin (Frontier Science, Ishikari, Japan), vesicular GABA transporter (VGAT, also named solute carrier family 32 member 1; Frontier Science), synaptophysin (Frontier Science), lysosomal-associated membrane protein 1 (LAMP1; R\&D Systems, Minneapolis, $\mathrm{MN}$ ), and glial fibrillary acidic protein (GFAP; SigmaAldrich, St. Louis, MO), respectively, were purchased commercially.

\section{Sampling for Morphologic Analysis}

CTSD $^{\text {Flox/Flox }}$;GRID2 ${ }^{+/ \text {Cre }}$ and their control littermates at $\mathrm{P} 0, \mathrm{P} 7, \mathrm{P} 14, \mathrm{P} 21, \mathrm{P} 29$, and $\mathrm{P} 40$ and 2 and 3 months $(n=3$ for each stage and genotype) and $\mathrm{Atg} 7^{\text {Flox/Flox }} ; \mathrm{GRID}^{+/ \text {Cre }}$ and their control littermates at P14 and P40 and 1, 2, and 3 months ( $n=3$ for each stage and genotype) were deeply anesthetized with pentobarbital $(25 \mathrm{mg} / \mathrm{kg}$ i.p.) and fixed by cardiac perfusion with $4 \%$ paraformaldehyde buffered with $0.1 \mathrm{~mol} / \mathrm{L}$ phosphate buffer ( $\mathrm{PB} ; \mathrm{pH}$ 7.2) containing $4 \%$ sucrose for light and electron microscopic immunohistochemistry/cytochemistry, and $2 \%$ paraformaldehyde $-2 \%$ glutaraldehyde buffered with $0.1 \mathrm{~mol} / \mathrm{L}$ PB for conventional electron microscopy. For light microscopy, brain tissues were further immersed in the same fixative for 2 hours, and they were processed for paraffin sections and cryosections, as reported previously. ${ }^{5,26}$ For immunoelectron microscopy using ultrathin cryosections, ${ }^{3,14}$ cerebellar tissues were cut into small pieces and further immersed in the same fixative for 2 hours. After being washed thoroughly with $7.5 \%$ sucrose in $0.1 \mathrm{~mol} / \mathrm{L} \mathrm{PB}(\mathrm{pH} 7.2)$, the samples were immersed in $2.3 \mathrm{~mol} / \mathrm{L}$ sucrose in $0.1 \mathrm{~mol} / \mathrm{L}$ $\mathrm{PB}$ overnight at $4^{\circ} \mathrm{C}$ and quickly plunged into liquid nitrogen.

For conventional electron microscopy, 1-mm-thick sagittal slices of cerebellar tissue were prepared, immersed in the same fixative overnight, postfixed with $2 \% \mathrm{OsO}_{4}$ in $0.1 \mathrm{~mol} / \mathrm{L} \mathrm{PB}$, block-stained in $1 \%$ aqueous uranyl acetate, dehydrated with a graded series of alcohol, and embedded in Epon 812 (TAAB, Reading, UK). For light microscopic observations, semithin sections were cut at $1 \mu \mathrm{m}$ with a Leica UC6 ultramicrotome (Leica Microsystems, Vienna, Austria) and stained with toluidine blue. For electron microscopy, silver sections were cut with an ultramicrotome, stained with uranyl acetate and lead citrate, and observed with a Hitachi H-7100 or HT7700 electron microscope (Hitachi, Tokyo, Japan).

\section{Immunohistochemistry for Light Microscopy}

Deparaffinized or frozen sections were immunostained, as described previously. ${ }^{3,14}$ For detecting subunit c, active caspase-3 and Atg7 cryosections were subjected to heatmediated antigen retrieval in citrate buffer. ${ }^{12,27}$ The sections with or without antigen retrieval were treated with $0.3 \% \mathrm{H}_{2} \mathrm{O}_{2}$ in methanol for 30 minutes and incubated with $2 \%$ normal horse serum for 20 minutes at room temperature. They were then incubated overnight at $4^{\circ} \mathrm{C}$ with the following first antibodies: rabbit anti-rat CTSD (dilution 1:200), subunit c $(10 \mu \mathrm{g} / \mathrm{mL}), \mathrm{LC} 3 \mathrm{~A} / \mathrm{B}$ (dilution 1:100), Iba1 (dilution 1:200), active caspase-3 (dilution 1:50), Atg7 (dilution 1:50), and p62/SQSTM1 (dilution 1:200); rabbit or goat anti-calbindin (dilution 1:200); or anti-VGAT (dilution 1:200), goat anti-LAMP1 (dilution 1:100), or mouse antiGFAP (dilution 1:200). Further incubation was performed with biotinylated goat anti-rabbit or mouse, or rabbit antigoat IgG for 1 hour, and finally with peroxidaseconjugated streptavidin (Vector Laboratories, Burlingame, CA) for 30 minutes at room temperature. Other sections were incubated with goat anti-rabbit or horse anti-goat antibody conjugated to polymerized horseradish peroxidase (Vector Laboratories). Staining for peroxidase was performed using $0.0125 \%$ of $3,3^{\prime}$-diaminobenzidine tetrahydrochloride (Dojindo Laboratories, Kumamoto, Japan. or Wako Pure Chemical Industries) and $0.002 \% \mathrm{H}_{2} \mathrm{O}_{2}$ in 0.05 $\mathrm{mol} / \mathrm{L}$ Tris- $\mathrm{HCl}$ buffer $(\mathrm{pH}$ 7.6) for 10 minutes. Some sections were subsequently counterstained with hematoxylin. Digital images of the sections were captured using a standard light microscope (BX50; Olympus, Tokyo, Japan) equipped with a DP71 or DP72 digital imaging system (Olympus).

For triple staining of LC3, VGAT, and calbindin, immunofluorescence microscopy was performed, as described previously. ${ }^{14,26,28}$ Briefly, the sections were incubated with rabbit anti-LC3A/B (dilution 1:100), goat anti-VGAT (dilution 1:100), or guinea pig anti-calbindin (dilution 1:100) overnight at $4^{\circ} \mathrm{C}$, followed by incubation with a mixture of cyanine 2-, 3-, and 5-conjugated donkey anti-rabbit, anti-goat, or anti-guinea pig $\operatorname{IgG}$ (dilution 1:300 each; The Jackson Laboratory, Bar Harbor, ME), respectively, for 1 hour at room temperature. Coverslips were placed onto the stained sections with Vectashield Mounting Medium with DAPI (Vector Laboratories), and the sections were then viewed under a confocal laser-scanning microscope (Olympus FV1000). As controls, sections were incubated with nonimmunized goat, guinea pig, or rabbit serum diluted 1:100, followed by the respective secondary antibodies, or with the secondary antibodies without incubation with the primary antibodies.

\section{Immunoelectron Microscopy}

Immunoelectron microscopy using ultrathin cryosections was performed, as described previously. ${ }^{3,14}$ Briefly, 
ultrathin cryosections were cut with a Leica UC7/FC7 at about $-120^{\circ} \mathrm{C}$. Sections of about $60 \mathrm{~nm}$ thickness were picked up with a 1:1 mixture of $2 \%$ methylcellulose and 2.3 $\mathrm{mol} / \mathrm{L}$ sucrose and incubated overnight at $4^{\circ} \mathrm{C}$ with rabbit anti-subunit c (dilution 1:10) or anti-synaptophysin (dilution 1:10) after incubation with goat anti-rabbit $\operatorname{IgG}$ conjugated with $10 \mathrm{~nm}$ of colloidal gold particles (dilution 1:40; British Biocell International, Cardiff, UK) for 1 hour at room temperature. The sections were embedded in a thin layer of $2 \%$ methylcellulose with $0.4 \%$ uranyl acetate $(\mathrm{pH} 4.0)$, airdried, and then observed with a Hitachi H-7100 electron microscope. For the control experiments, ultrathin sections were reacted only with the gold particle-conjugated secondary antibody.

\section{TUNEL Staining}

To detect nuclear DNA fragmentation, terminal deoxynucleotidyl transferase-mediated dUTP nick-end labeling (TUNEL) staining was applied to cryosections, according to the previous method ${ }^{4,26}$ with minor modifications. Briefly, sections were pretreated with $10 \mu \mathrm{g} / \mathrm{mL}$ proteinase $\mathrm{K}$ for 10 minutes at room temperature, incubated with $100 \mathrm{U} / \mathrm{mL}$ terminal deoxynucleotidyl transferase (Promega, Madison, WI) and $10 \mathrm{nmol} / \mathrm{mL}$ biotinylated 16-2'-dUTP (Roche Applied Science, Indianapolis, IN) in terminal deoxynucleotidyl transferase buffer $(100 \mathrm{mmol} / \mathrm{L}$ sodium cacodylate, $\mathrm{pH} 7.0,1 \mathrm{mmol} / \mathrm{L}$ cobalt chloride, $50 \mu \mathrm{g} / \mathrm{mL}$ gelatin) in a humid atmosphere at $37^{\circ} \mathrm{C}$ for 1 hour, followed by further incubation with peroxidase-conjugated streptavidin at room temperature for 1 hour. Staining for peroxidase was performed in the manner described above.

\section{Cell Counting}

The number of PCs was quantified according to a method described with minor modifications by Nishiyama et al. ${ }^{19}$ In brief, paraffin sections from $C T S D^{F / F}$;GRID2$C r e$, and $C T S D^{F / F}$ mice at $\mathrm{P} 29$ and $\mathrm{P} 30$ and 2 months and $\operatorname{Atg} 7^{F / F}$;GRID2-Cre and $\operatorname{Atg} 7^{F / F}$ mice at 2 and 3 months ( $n=3$ for each group) were immunostained for calbindin, as described above. Images were taken from four lobules (lobules III, IV, VIII, and IX) using a $20 \times$ objective lens, and these were analyzed using ImageJ software version 1.44o for Macintosh (NIH, Bethesda, MD). Segmented lines were connected between the center of the soma of each PC along the entire length of its layer in the optical section; the distance of this line was then measured, and the number of PCs per unit length was calculated from each lobule and averaged.

\section{Rotarod Performance Test}

A rotarod performance test was performed, as reported previously with some modifications. ${ }^{29}$ A rotarod machine with automatic timers and falling sensors (MK-660D;
Muromach Kikai, Tokyo, Japan) was used. Male mice at 7 weeks of age ( $n=3$ for each genotype) were placed on a rotating rod that was $3 \mathrm{~cm}$ in diameter and covered with rubber. The rotation of the rod was accelerated from 3 to 35 r.p.m. over a period of 5 minutes, and the time of each fall from the rotating rod was recorded. The time of the first fall on the third trial was recorded.

\section{Sample Preparations for Biochemical Analyses}

CTSD $^{+/+}$, CTSD $^{+/-}$, and $C T S D^{-/-}$mice at P23 $(n=3$ per each genotype) were euthanized by decapitation, and the whole brains were rapidly dissected and divided into halves. The left and right brains were separately frozen in liquid nitrogen and stored at $-80^{\circ} \mathrm{C}$ until used.

\section{Immunoblot Analysis}

Each tissue was independently homogenized in a lysis buffer containing $50 \mathrm{mmol} / \mathrm{L}$ Tris- $\mathrm{HCl}, \mathrm{pH} 7.5,150 \mathrm{mmol} / \mathrm{L}$ $\mathrm{NaCl}, 1 \%$ Triton $\mathrm{X}-100$ and a protease inhibitor cocktail (Nacalai Tesque, Kyoto, Japan) using a Polytron homogenizer (Kinematica, Lucerne, Switzerland) at $80 \%$ of the maximal speed. After being centrifuged twice at $10,500 \times g$ for 10 minutes at $4^{\circ} \mathrm{C}$, the supernatant fluids were measured for protein concentrations using the BCA protein assay system (Pierce, Rockford, IL). The samples were then analyzed by $12.5 \%$ SDS-PAGE. Electrophoretic transfer of proteins from polyacrylamide gels to a polyvinylidenefluoride membrane (Immobilon-P; Millipore Co., Bedford, MA) was performed as described previously. ${ }^{14}$ The sheets were soaked in phosphate-buffered saline containing 5\% bovine serum albumin and then incubated overnight with anti-CTSD (dilution 1:1000) and further with swine antirabbit IgG (dilution 1:1000; Dako, Glostrup, Denmark). The membranes treated with Immobilon Western Chemiluminescent HRP Substrate (Millipore Co.) were observed using an LAS-3000 mini system (Fuji Photo Film, Tokyo, Japan).

\section{Measurement of CTSD Activity}

Proteolytic activity of CTSD in the brain tissues of $C T S D^{+/+}$, CTSD $^{+--}$, and CTSD $^{-1-}$ mice at P23 $(n=3$ per each genotype) was measured using fluorescent peptide substrates as previously described. ${ }^{30}$ Briefly, each brain was homogenized in $0.25 \mathrm{~mol} / \mathrm{L}$ sucrose, $10 \mathrm{mmol} / \mathrm{L}$ HEPES, $\mathrm{pH} \mathrm{7.4}$, and 1 $\mathrm{mmol} / \mathrm{L}$ dithiothreitol and centrifuged at $15,000 \times g$ for 10 minutes, and the supernatant fluid $(10 \mu \mathrm{L}$ each) was incubated in an opaque 96-well plate with $190 \mu \mathrm{L}$ of a reaction buffer $[50 \mathrm{mmol} / \mathrm{L}$ sodium acetate buffer, $\mathrm{pH} 4.0$, containing $10 \mu \mathrm{mol} / \mathrm{L}$ of MOCAc-Gly-Lys-Pro-Ile-Leu-Phe-Phe-ArgLeu-Lys (Dnp)-Arg-NH ${ }_{2}$; Peptide Institute, Inc., Minoo, Japan] and $1 \mu \mathrm{g} / \mathrm{mL}$ leupeptin at $37^{\circ} \mathrm{C}$. The fluorescence intensity of reacted samples at $390 \mathrm{~nm}(E x=330 \mathrm{~nm})$ was monitored for 15 minutes at 30 -second intervals using a 
SpectraMax M2 (Molecular Devices, Sunnyvale, CA), and initial rate was determined from the initial velocity using MOCAc-Pro-Leu-Gly as a reference compound. The accumulation of fluorescence was shown linear for at least 15 minutes. Protein concentrations in each lysate were determined by BCA protein assay, as described above. The experiments were repeated three times with samples from each brain, and the data from three animals in each group were averaged.

\section{Statistical Analysis}

By using Kaleidagraph software version 4.0 Mac (Albeck Software, Reading, PA), statistical significance was analyzed by $t$-test or one-way analysis of variance, where all pairwise multiple comparison procedures were performed using Tukey's post hoc test. Data are expressed as means \pm SEM. $P<0.05$ was considered significant.

\section{Results}

\section{Specific Deletion of CTSD in PCs Causes Ataxia}

Here, we generated $C T S D^{\text {Flox/Flox }}$ mice carrying two loxP sites in intron-1 and -2 of the CTSD gene (Supplemental Figure S1A). By intercrossing $C T S D^{\text {Flox } F l o x}$ mice with GRID2 ${ }^{+/ C r e}$ mice, where Cre recombinase is expressed in PCs under the control of the GRID2 promoter, ${ }^{17}$ we obtained PC-specific $C T S D$-deficient mice $\left(C T S D^{\text {Flox/Flox }}\right.$;GRID2 ${ }^{+/ C r e}$, hereafter referred to as $C T S D^{F / F}$;GRID2-Cre mice). The littermates from the same breeding pairs carrying the floxed $C T S D$ gene but no $C r e$ gene $\left(C T S D^{F / F} ; \mathrm{GRID}^{+/+}\right)$were used as the control.

The efficiency of the GRID2 promoter was previously demonstrated by crossing the GRID2 $2^{+/ C r e}$ mice with a Cre-inducible $l a c Z$ reporter mouse strain (CAG-CAT-Z11); selective Cre expression in the PCs was observed at least from around P7. ${ }^{17}$ With the use of genomic PCR analysis, we confirmed that Cre-mediated recombination specifically occurred in the cerebellum from $\mathrm{P} 7$, but neither in the tail, the olfactory bulb, nor the hippocampus of the $C T S D^{F / F}$;GRID2-Cre mice at P29. In contrast, no spontaneous recombination was observed in $C T S D^{F / F}$ mice that did not have the GRID2-Cre transgene (Supplemental Figure S1, B and C).

Although conventional $C T S D^{-1-}$ mice die at P26 \pm 1 day, ${ }^{13} C T S D^{F / F}$;GRID2-Cre mice lived to adulthood and were fertile. $C T S D^{F / F}$;GRID2-Cre mice were indistinguishable in appearance from their $C T S D^{F / F}$ littermates until they showed a mild ataxic gait and an abnormal limbclasping reflex at about 5 weeks of age (data not shown). In the rotarod performance test, the length of time that the $C T S D^{F / F}$;GRID2-Cre mice could stay on the rotating rod was significantly shorter than that for their control littermates at 7 weeks of age (Supplemental Figure S1D). After 2 months of age, $C T S D^{F / F}$;GRID2-Cre mice showed severe ataxia and mild weight loss. Such pathologic phenotypes in $C T S D^{F / F}$;GRID2-Cre mice were manifested much slower and milder than those in conventional $C T S D^{-1-}$ mice.

\section{Specific Deletion of CTSD in PCs Induces Neuropathologic Phenotypes of NCLs}

At as early as P7, when positive granular staining for CTSD was abundant in PCs and in other cells in the cerebellum of control littermates (Supplemental Figure S2, A and C), a considerable part of the PCs of the $C T S D^{F / F}$;GRID2-Cre mice was negative for CTSD immunoreactivity; however, some PCs of these mice still showed weak granular immunoreactivity for CTSD (Supplemental Figure S2B). At P14 depletion of immunoreactivity for CTSD was confirmed specifically in PCs of the $C T S D^{F / F}$;GRID2-Cre mouse cerebellum (Supplemental Figure S2D).

As we have shown in neurons of $C T S D$-deficient central nervous system tissue by electron microscopy and immunohistochemistry/cytochemistry, ${ }^{3,5}$ similar neuropathologic results were also obtained in CTSD-deficient PCs; granular osmiophilic deposits (GRODs), fingerprint profiles, and autophagosomes, which are morphologic hallmarks of NCL due to $C T S D$ deficiency, occupied the perikarya of the mutant PCs (Figure 1, A-E), but they were not detected in control PCs (Figure 1, F and G). Immunohistochemistry for LAMP1 also demonstrated lysosomal storage in CTSDdeficient PCs, which possessed coarse and intense immunoreactivity for LAMP1 accumulating in the perikaryal region (Supplemental Figure S2F). In the control PCs, lysosomes immunopositive for LAMP1 were scattered throughout their perikarya (Supplemental Figure S2E). Notably, the degenerating PCs with pyknotic nuclei were full of LAMP1-positive lysosomes in the perikarya and dendrites (Supplemental Figure S2F). Immunohistochemistry detected intense immunoreactivity for subunit $\mathrm{c}$ of mitochondrial ATP synthase only in CTSD-deficient PCs, whereas immunoelectron microscopy has detected this both in GRODs and mitochondria (Figure $1 \mathrm{H}$ and Supplemental Figure S2, G and $\mathrm{H}$ ). Moreover, intense granular immunostaining of LC3 has confirmed the accumulation of autophagosomes in the perikarya and dendrites of $C T S D$ deficient PCs (Supplemental Figure S2J), whereas the PCs of the $C T S D^{F / F}$ mice exhibited diffuse immunoreactivity for LC3 (Supplemental Figure S2I). These results suggest that PCs in the $C T S D^{F / F}$;GRID2-Cre mice exhibit neuropathologic phenotypes of NCLs.

\section{Progressive and Cell Autonomous Neurodegeneration in CTSD-Deficient PCS}

The size and foliation of the cerebellum in mice with CTSDdeficient PCs appeared normal at least until 2 months of age, at which time the PCs were completely lost or largely altered when examined by immunohistochemistry for calbindin (Figure 2 and Supplemental Figure S3). Mutant PCs 

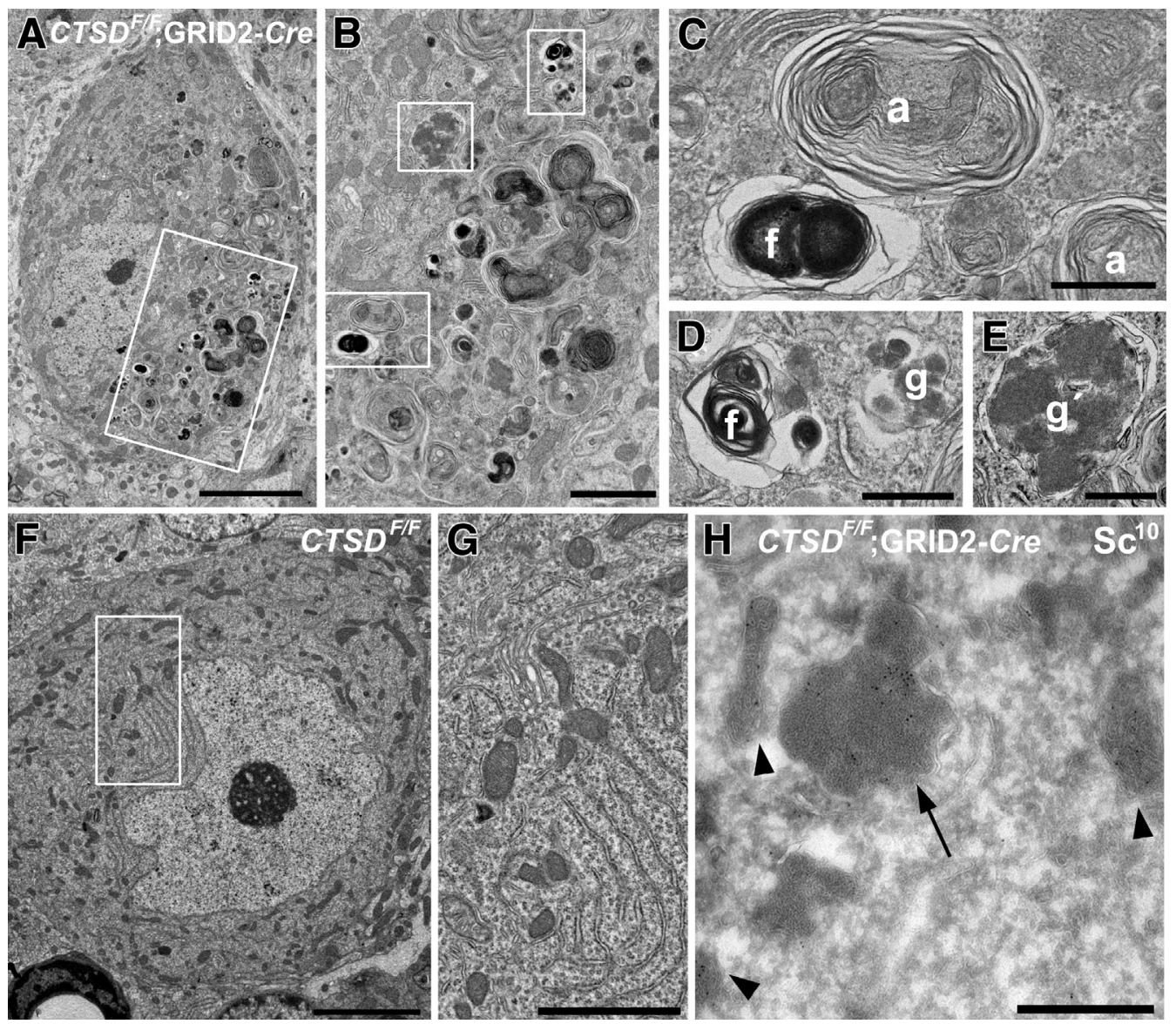

Figure 1 A-G: Electron microscopy of the perikarya of the PCS of $C T S D^{F / F} ; G R I D 2-C r e(\mathbf{A}-\mathbf{E})$ and $C T S D^{F / F}(\mathbf{F}$ and $\mathbf{G})$ mice at P29. The boxed areas in $\mathbf{A}$ and $\mathbf{F}$ are shown at higher magnification in $\mathbf{B}$ and $\mathbf{G}$, respectively. The lower, upper, and middle boxed areas in $\mathbf{B}$ are shown at higher magnification in $\mathbf{C}$, $\mathbf{D}$ (rotated $90^{\circ}$ counterclockwise), and $\mathbf{E}$, respectively. In $C T S D^{F / F} ; G R I D 2-C r e$ mice GRODs ( $g$ ), fingerprint profiles (f), and autophagosomes (a) accumulate in the perikarya of the PCs (C-E). Note that some GRODs $\left(g^{\prime}\right)$ are enwrapped by autophagosomes $(\mathbf{E})$. H: Immunoelectron microscopy using ultrathin cryosections of the CTSD-deficient PCS at P40. Gold particles $(10 \mathrm{~nm}$ ) indicating Sc specifically localizes in the GRODs (arrow) in addition to mitochondrial inner membranes (arrowheads). Scale bars: $5 \mu \mathrm{m}$ (A and F); $2 \mu \mathrm{m}$ (B and G); $0.5 \mu \mathrm{m}$ (C-E, and H). GROD, granular osmiophilic deposit; P, postnatal day; PC, Purkinje cell; Sc, subunit $\mathrm{c}$ of mitochondrial ATP synthase.

exhibited no clear-cut alteration in immunoreactivity for calbindin until 3 weeks of age (Supplemental Figure S3, A-F). As mutant PCs gradually disappeared from the PC layer of the cerebellum after P29, immunoreactivity for calbindin was largely diminished in the molecular and PC layers. At 2 months, PCs with calbindin immunoreactivity largely disappeared at the rostral and caudal lobes (Figure 2, $\mathrm{A}-\mathrm{F})$, as evidenced by the quantification of the remaining PCs of the $C T S D^{F / F}$;GRID2-Cre mice at P29, P40, and 2 months (Figure $3 \mathrm{~A}$ ).

In a semithin section of the cerebellar cortex of $C T S D^{F / F}$;GRID2-Cre mice at $\mathrm{P} 40$, the remaining PCs were densely stained with toluidine blue (Figure 3C), suggesting the degeneration of the CTSD-deficient PCs. In conventional $C T S D$-deficient mice neuronal cell death occurs in the hippocampal pyramidal layer at their terminal stage as shown by TUNEL staining and immunohistochemistry for the active form of caspase- $3 .{ }^{12}$ Therefore, we compared the type of cell death of degenerating PCs and hippocampal pyramidal neurons of the $C T S D^{F / F}$;GRID2-Cre and conventional CTSDdeficient mice, respectively, by TUNEL staining and immunohistochemistry for active caspase-3, which were performed according to procedures established in our previous studies., ${ }^{4,26}$ For this purpose, we generated conventional $C T S D$-deficient mice (hereafter referred to as $C T S D^{-1-}$ mice) by crossing $C T S D^{F / F}$ mice with CAGCre mice that express Cre recombinase ubiquitously. ${ }^{24}$ $C T S D^{-1-}$ mice died at around P26 as in the conventional CTSD-deficient mice reported previously. ${ }^{3,13}$ In the brain tissue of the $C T S D^{-1-}$ mice, CTSD was confirmed to be deficient as evidenced by Western blot analysis, activity assay, and immunohistochemistry for CTSD (Supplemental Figure S1, E-H). There were neither TUNEL-negative nor active caspase-3-positive hippocampal pyramidal neuron and PCs of the $C T S D^{+/+}$ mouse at $\mathrm{P} 23$ and the $C T S D^{F / F}$ mouse at $\mathrm{P} 40$, respectively (Supplemental Figure S4, A, C, E, and G). Consistent with the previous study, ${ }^{12}$ some of the hippocampal pyramidal neurons of the $C T S D^{-1-}$ possessed 


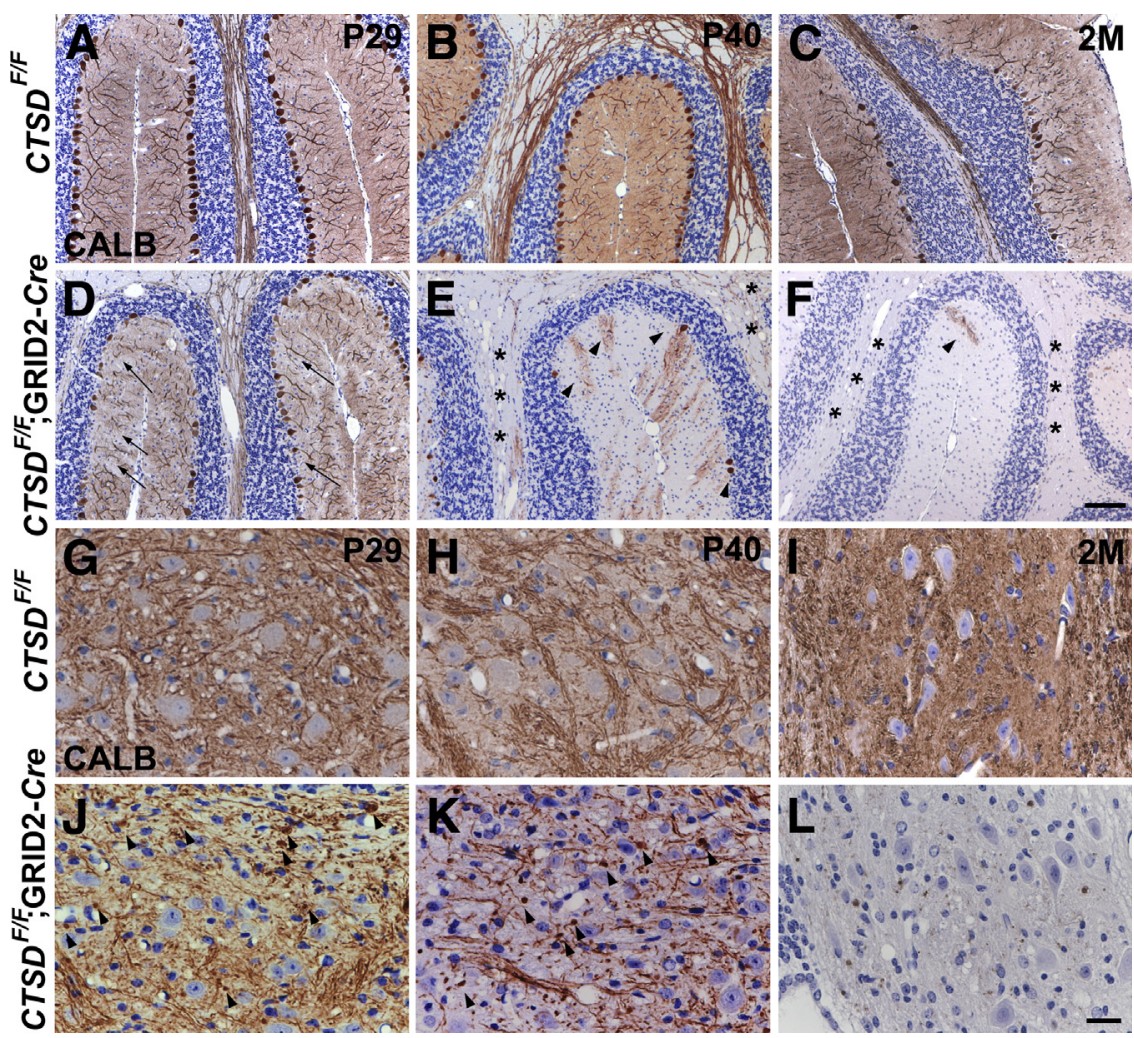

Figure 2 Immunohistochemistry for CALB in the cerebellar cortex $(\mathbf{A}-\mathbf{F})$ and $D C N(\mathbf{G}-\mathbf{L})$ obtained from $C T S D^{F / F}(\mathbf{A}-\mathbf{C}$ and $\mathbf{G}-\mathbf{I})$ and $C T S D^{F / F}$; GRID2-Cre (D-F and $\mathbf{J}-\mathbf{L})$ mice at P29 (A, D, G, and $\mathbf{J}), \mathrm{P} 40$ (B, E, $\mathbf{H}$, and $\mathbf{K})$, and at $2 \mathrm{M}(\mathbf{E}, \mathbf{F}, \mathbf{I}$, and $\mathbf{L}$ ). A-F: At P29 partial defect of the immunoreactivity for CALB was observed in the molecular layer of the cerebellar cortex from the $C T S D^{F / F}$; GRID2-Cre mice (D, arrows). After P40 only a few CALB-positive $P C s$ remain in the cerebellar cortex of the $C T S D^{F / F} ;$ GRID2-Cre mice (E and $\mathbf{F}$, arrowheads). In the cerebellar white matter of the $C T S D^{F / F}$;GRID2-Cre mice, the immunoreactivity for CALB is massively reduced at P40 and no longer detectable at $2 \mathrm{M}$ (asterisks). G-L: In the DCN of the $C T S D^{F / F}$;GRID2-Cre mice, immunoreactivity for CALB is reduced at P29 and P40, whereas swollen axons with CALB immunoreactivity are distinct ( $\mathbf{J}$ and $\mathbf{K}$, arrowheads). At 2M CALB-positive axons of the CTSD-deficient PCS are no longer detectable in the DCN. Scale bars: $100 \mu \mathrm{m}(\mathbf{A}-\mathbf{F}) ; 20 \mu \mathrm{m}$ (G-L). 2M, 2 months; CALB, calbindin; DCN, deep cerebellar nuclei; $\mathrm{P}$, postnatal day; $\mathrm{PC}$, Purkinje cell.

pyknotic nuclei and were positive for TUNEL or active caspase-3 at P23 (Supplemental Figures $\mathrm{S} 1 \mathrm{H}$ and $\mathrm{S} 4, \mathrm{~B}$ and D). However, the degenerating PCs of the $C T S D^{F / F}$;GRID2-Cre at P40 were negative for TUNEL and also for active caspases-3 (Supplemental Figure S4, $\mathrm{F}$ and $\mathrm{H}$ ). In electron microscopy the morphologic features of such degenerating PCs were distinct from the typical morphologic features of apoptosis, as described below (Figure 3, D-H). In the earlier stages of degeneration, PCs possessed irregularly shaped nuclei with small patches of clumped chromatin. The nuclear membranes remained intact, but the cisternal spaces of the nuclear envelope and endoplasmic reticulum were enlarged (Figure 3, D and E). In the later stages of degeneration, PCs became significantly electron dense. Small patches of clumped chromatin were also distinct in the nuclei, and a nuclear envelope was no longer discernible (Figure 3, F and G). Notably, autophagosomes and GRODs massively accumulated in the perikarya, and synaptic connections were still preserved on the surface membranes of degenerating PCs (Figure 3H). These findings were consistent with massive accumulation of LAMP1-positive lysosomes in the degenerating $\mathrm{PC}$ as mentioned above (Supplemental Figure S2F).

In the cerebellar cortex of the $C T S D^{F / F}$;GRID2-Cre mice, immunoreactivity for GFAP was increased at all stages examined, and the somata of the PCs were delineated by the surrounding activated Bergmann glia and/or astrocytes (Supplemental Figure S4, I, J, M, N, Q and R), which suggested chronic activation. In contrast, Iba1positive-activated microglia were detected in the cerebellar cortex of the $C T S D^{F / F}$;GRID2-Cre mice only at P29 and P40 (Supplemental Figure S4, P and L). Two months after birth, when most PCs had disappeared, microglial cells in the $C T S D^{F / F}$;GRID2-Cre mice showed no activation (Supplemental Figure S4T) as in the controls (Supplemental Figure S4, K, O, and S), suggesting that the activation of microglial cells had occurred in a transient manner. The extent of immunohistochemistry and electron microscopy showed that $C T S D$-deficient PCs were not surrounded by activated microglial cells.

As the results of the present study show, CTSD deficiency specifically in PCs caused cell-autonomous neuronal death of PCs in a caspase-independent fashion within 2 months of birth. The ataxic phenotype of the $C T S D^{F / F}$;GRID2-Cre mice became apparent when a substantial number of PCs started to die, and the process progressed thereafter.

\section{Axonal Swelling in Degenerating CTSD-Deficient PCS}

Accompanying with the loss of PCs in the $C T S D^{F / F}$;GRID2Cre mice, the immunoreactivity for calbindin in the cerebellar white matter and deep cerebellar nuclei (DCN) of the $C T S D^{F / F}$;GRID2-Cre mice was rapidly reduced between P29 and P40 compared with the controls (Figure 2, G-I) and no longer detectable at 2 months (Figure 2, D-F and J-L). Notably, swollen axons with calbindin immunoreactivity were distinct in CTSD-deficient PCs at P29 and P40 

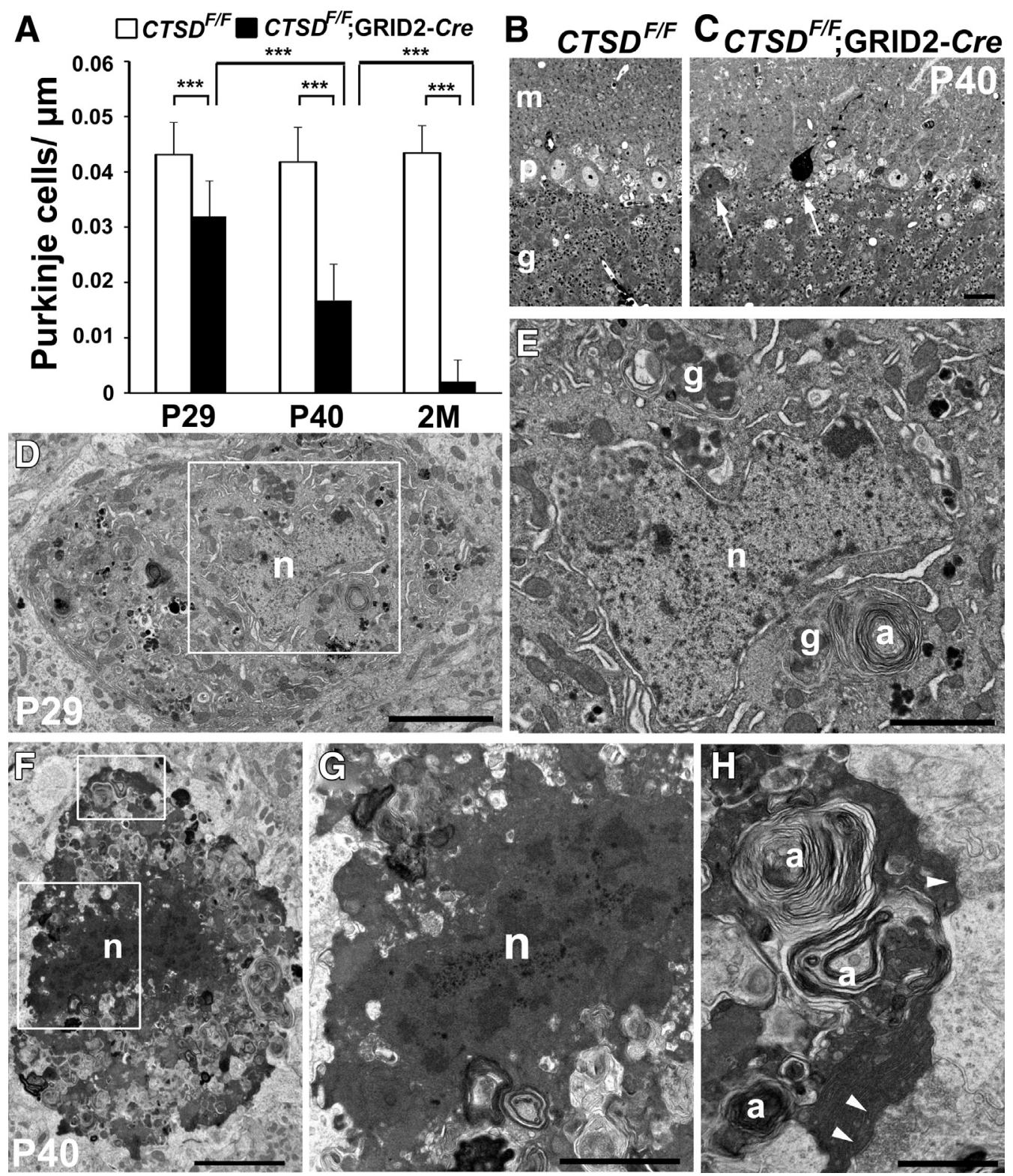

Figure 3 A: Quantification of surviving PCS in the $C T S D^{F / F}$ and $C T S D^{F / F} ; G R I D 2-C r e$ mice at P29 and P40 and at $2 \mathrm{M}$. B and C: Semithin sections of the cerebellar cortex of $C T S D^{F / F}$ (B) and $C T S D^{F / F} ; G R I D 2-C r e(C)$ mice at P40. In $C T S D^{F / F} ; G R I D 2-C r e$ mice degenerating PCs with higher density are observed (arrows). D-H: Electron microscopy of the dying PCs of the $C T S D^{F / F} ; G R I D 2-C r e$ mice at P29 (D and $\left.\mathbf{E}\right)$ and P40 (F-H). The boxed area in $\mathbf{D}$ is shown at higher magnification in $\mathbf{E}$. The lower and upper boxed areas in $\mathbf{F}$ are shown at higher magnification in $\mathbf{G}$ and $\mathbf{H}$ (rotated $90^{\circ}$ clockwise), respectively. $\mathbf{D}$ and $\mathbf{E}$ : At P29, the degenerating PC possessed irregularly shaped nuclei ( $n$ ) with small patches of clumped chromatin. The perikaryon was filled with autophagosomes (a) and granular osmiophilic deposits $(\mathrm{g})$. The perinuclear space and lumen of the endoplasmic reticulum were enlarged. F-H: At P40 nuclei with small patches of clumped chromatin were also observed in the degenerating PC with higher electron density, where the nuclear envelope was indiscernible. Autophagosomes accumulated in the perikaryon in massive amounts. The arrowheads indicate a synaptic connection on the degenerating PC. Data are expressed as means \pm SEM. $n=3$ slices. ${ }^{* *} P<0.001$ (one-way analysis of variance with Tukey's post hoc test). Scale bars: $20 \mu \mathrm{m}(\mathbf{B}$ and $\mathbf{C}) ; 5 \mu \mathrm{m}(\mathbf{D}$ and $\mathbf{F}) ; 2 \mu \mathrm{m}(\mathbf{E}$ and G); and $1 \mu \mathrm{m}(\mathbf{H}) .2 \mathrm{M}, 2$ months; g, granular cell layer; m, molecular layer; n, nuclei; $\mathrm{p}$, Purkinje cell layer; PC, Purkinje cell.

(Figure 2, $\mathrm{J}$ and $\mathrm{K}$ ). Immunolabeling of calbindin revealed that such axonal swellings of CTSD-deficient PCs emerged in the DCN region at P14 and increased in number after P21 (Supplemental Figure S3, G-I). Such instances of axonal swelling (spheroids) were, although smaller in number, also observed in the white matter outside the DCN region and in the granular cell layers (Supplemental Figure S3, E and F). To further explore the neuropathologic change of the axon terminals of CTSD-deficient PCs we performed immunohistochemistry for VGAT, which is specifically localized in the axon terminals surrounding neuronal cell bodies in the DCN as shown in the controls (Supplemental Figure $\mathrm{S} 3, \mathrm{~J}$ and $\mathrm{M}-\mathrm{O}$ ). As with the immunostaining for calbindin, VGAT-positive axon terminals of mutant PCs around neurons in the DCN gradually disappeared after P29 (Supplemental Figure S3, K, L, and P-R). In the present study, the VGAT-immunopositive presynaptic terminals of PCs deficient in CTSD remained largely intact, but 
spheroids in the distal axons close to the presynaptic terminal and the cerebellar white matter were definitely positive for VGAT after P21 (Supplemental Figure S3, L, P, and Q). These findings suggest that axonal swelling accompanied the degenerative changes in CTSD-deficient PCs and appeared predominant in the distal axons nearby the axon terminals of the PCs.

Aberrant Membranous Structures and AutophagosomeLike Organelles Accumulate in the Spheroids and Axon Terminals of CTSD-Deficient PCS

Electron microscopy showed that along myelinated axons in the white matter of $C T S D^{F / F}$;GRID2-Cre mice, a cluster of tubulovesicular structures derived from endoplasmic reticulum that were larger in diameter than synaptic vesicles were observed (Figure 4C). These vacuolar structures were identical to the so-called honeycomb-like tubular structures that are normally seen in a variety of pathologic conditions of rodent PCs. ${ }^{31-33}$ Indeed, such honeycomb-like tubular structures were detected in the axons of $C T S D^{F / F}$ PCs (Figure 4B), but these structures were more frequent in PCs deficient in CTSD than in their control counterparts (Figure 4A). Furthermore, moderately electron-dense materials surrounded by double membranes were observed (Figure 4, D and E) and were also observed in axons in the corpus callosum of $C T S D^{-1-}$ mice and in mice doubly deficient in cathepsins $B$ and L. $^{5}$ Such abnormal
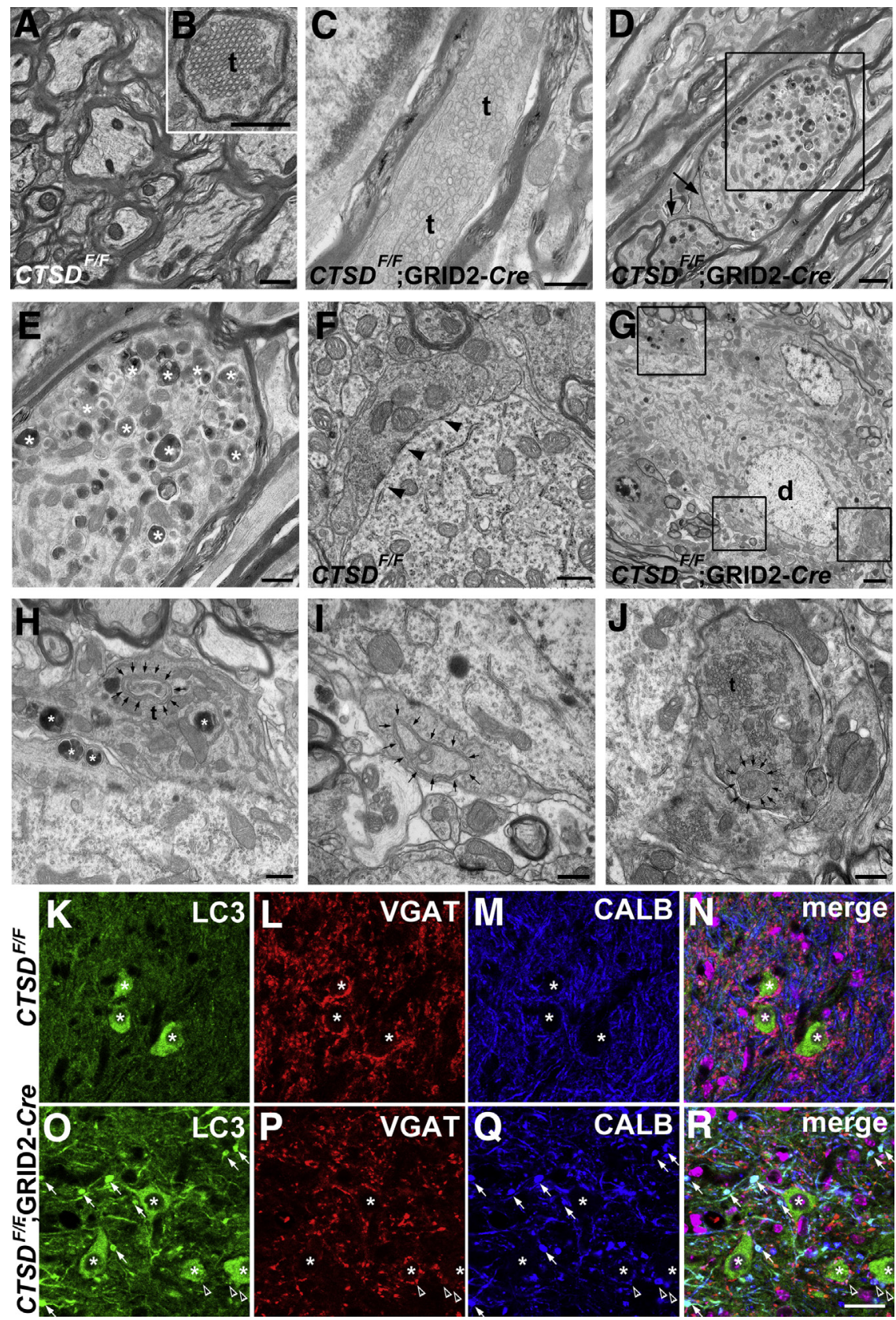

Figure 4 A-J: Electron microscopy of axons $(\mathbf{A}-\mathbf{E})$ and presynaptic terminals $(\mathbf{G}-\mathbf{J})$ of the $\mathrm{PCS}$ of the $C T S D^{F / F}(\mathbf{A}, \mathbf{B}$, and $\mathbf{E})$ and $C T S D^{F / F} ;$ GRID2-Cre (C-E and $\mathbf{G}-\mathbf{J}$ ) mice at P29. The boxed area in $\mathbf{D}$ is shown at higher magnification in $\mathbf{E}$. The upper, lower middle, and lower right boxed areas in $\mathbf{G}$ are shown at higher magnification in $\mathbf{H}, \mathbf{I}$, and $\mathbf{J}$, respectively. A-C: Along the axons of the PCS, the accumulation of a cluster of honeycomb-like tubular $\mathrm{t}$ was observed both in the $C T S D^{F / F}$ (B) and $C T S D^{F / F}$;GRID2-Cre mice. The CTSD-deficient PC accumulation of these structures are more pronounced (C). D and E: In the axonal spheroids of the CTSD-deficient PCS, electron-dense structures with double membranes accumulate $(\mathbf{E}$, asterisks). Note the thinner myelin sheath around these spheroids (D, arrows). F: Typical symmetrical synapses of PCs around neurons in the DCN of the $C T S D^{F / F}$ mice (arrowheads). G-J: At the presynaptic terminal of the CTSD-deficient PCS, nascent autophagosomes with double membranes (arrows), electron-dense structures with double membrane (asterisks), and a cluster of $t$ were observed near synaptic vesicles and mitochondria (d, a nucleus of the neuron of DCN). K-R: Triple immunofluorescent staining for LC3 (green), VGAT (red), and CALB (blue) in the DCN of the $\operatorname{CTSD}^{F / F}(\mathbf{K}-\mathbf{N})$ and $C T S D^{F / F} ;$ GRID2-Cre $(\mathbf{0}-\mathbf{R})$ mice at P40. Counterstained with DAPI (magenta). In the $C T S D^{F / F}$ mice, diffuse staining for LC3 is observed in the cytoplasm of the DCN neurons (asterisks), whereas the immunoreactivity for LC3 is weak in the axons and axon terminals of PCs. However, in the $C T S D^{F / F}$;GRID2-Cre mice intense immunoreactivity for $\mathrm{LC} 3$ is observed in the CALBpositive axons and axonal spheroids ( $\mathbf{0}, \mathbf{Q}$, and $\mathbf{R}$, arrows) and in the CALB- and VGAT-positive axon terminals of PCS surrounding DCN neurons (open arrowheads). Scale bars: $20 \mu \mathrm{m}(\mathbf{K}-\mathbf{R}) ; 2 \mu \mathrm{m}(\mathbf{G})$; $1 \mu \mathrm{m}$ (A and $\mathbf{D}) ; 0.5 \mu \mathrm{m}$ (B, C, E, F, and $\mathbf{H}-\mathbf{J})$. CALB, calbindin; DCN, deep cerebellar nuclei; LC3, light chain 3; P, postnatal day; PC, Purkinje cell; $t$, tubulovacuolar structures; VGAT, vesicular GABA transporter. 
membrane-bound structures accumulated in the spheroids (Figure 4, D and E) and were often surrounded by thinner myelin sheaths. In the axon terminals of the PCs of $C T S D^{F / F}$ mice, which formed symmetrical synapses around neurons in the DCN, synaptic vesicles and mitochondria accumulated (Figure 4F). However, in the axon terminals of the CTSD-deficient PCs, honeycomb-like vesicular structures and double membrane-bound structures and/or synaptic vesicles also accumulated (Figure 4, G-J). In the present study, GRODs and fingerprint profiles were undetectable in the axons and presynaptic terminals of CTSD-deficient PCs, whereas such structures dominantly accumulated in the somato-dendrites of these PCs, as demonstrated above.

We have previously shown that immunoreactivity for LC3 is intensely granular in neuronal perikarya, dendrites, and axonal swelling in the cerebral and cerebellar neurons deficient in $C T S D$ or cathepsins $B$ and $L,{ }^{5}$ which also was seen in CTSD-deficient PCs in the perikarya (Supplemental Figure S2J). Moreover, triple staining for LC3, VGAT, and calbindin in the DCN of $C T S D^{F / F}$ and $C T S D^{F / F}$;GRID2-Cre mice revealed intense immunoreactivity for $\mathrm{LC} 3$ in the axonal spheroids and presynaptic terminals of CTSD-deficient PCs (Figure 4, K-R), indicating that autophagosomerelated structures massively accumulated in the axonal spheroids and presynaptic terminals in CTSD-deficient PCs. However, in the present study no GRODs were detected in the axons of $C T S D$-deficient PCs.

\section{PCs Deficient in CTSD Are More Vulnerable Than Those Deficient in Atg7}

Because ataxia is a common symptom in inherited neurodegenerative diseases due to the mutations in human CTSD and $A \operatorname{tg} 5^{9,20}$ and in Atg5- or Atg7-deleted mice specifically in PCs under the control of Pcp2 (L7) promoter, ${ }^{18,19}$ we performed a precise comparison of the neuropathologic findings between $C T S D$ - and Atg7-deficient PCs by generating novel $\mathrm{PC}$-specific Atg7-deficient mice (referred to as $A \operatorname{tg} 7^{F /}$ ${ }^{F}$;GRID2-Cre mice). The PCs of the $A \operatorname{tg} 7^{F / F}$ mice at P14 and $\mathrm{P} 29$ exhibited weak but distinct immunoreactivity for $\mathrm{Atg} 7$ in the cytoplasm (Supplemental Figure S5, A and E), whereas PCs of the $\operatorname{Atg} 7^{F / F}$;GRID2-Cre mice Atg7 immunostaining was largely diminished at P14 and P29. No difference was found in the intensity for Atg7 immunoreactivity in the molecular layer of $A \operatorname{tg} 7^{F / F}$ and $A \operatorname{tg} 7^{F / F}$;GRID2-Cre mice (Supplemental Figure S5, B and F), indicating that conditional Atg 7 deficiency in PCs of the $A \operatorname{tg} 7^{F / F}$;GRID2-Cre mice occurred at least at P14. It has been shown that inhibition of autophagy is correlated with accumulation of cytosolic aggregates containing ubiquitin and p62/SQSTM1, an autophagy substrate. ${ }^{18,34}$ In the PCs of the $\operatorname{Atg} 7^{F / F}$ mice the immunoreactivity for p62/SQSTM1 was diffuse at P14 and P29, whereas Atg7-deficient PCs at P14 and P29 possessed small inclusions intensely positive for p62/SQSTM1, confirming impaired autophagic activity in the Atg7-deficient PCs after P14 (Supplemental Figure S5, C, D, G, and H).
Compared with previous studies on PC-specific ablation of Atg 5 or Atg7, ${ }^{18,19}$ PC degeneration in $C T S D^{F / F}$;GRID2Cre mice occurred more rapidly; a large portion of the PCs of $A \operatorname{tg} 7^{F / F}$;GRID2-Cre mice had disappeared at 3 months of age (Figure 5C). Quantification of the remaining PCs of the CTSD and $\operatorname{Atg} 7^{F / F}$;GRID2-Cre mice at 2 months of age revealed that, although considerable numbers of Atg7deficient PCs survived, the CTSD-deficient PCs had largely disappeared (Figure 5C). At this stage, calbindin-positive axons along the cerebellar white matter and axonal spheroids and/or presynaptic terminals in the DCN were observed in $\mathrm{Atg} 7^{F / F}$;GRID2-Cre mice, whereas they were completely lost in $C T S D^{F / F}$;GRID2-Cre mice (Figure 5, A and B). Moreover, in contrast to the rapid disappearance of the VGAT-positive axonal spheroids and/or presynaptic terminals of CTSD-deficient PCs (Supplemental Figure S3, $\mathrm{P}-\mathrm{R}$ ), regional swelling became more pronounced in Atg7deficient PCs with age; at P40, huge VGAT-positive axonal spheroids occupied the DCN of $A \operatorname{tg} 7^{F / F}$;GRID2-Cre mice (Supplemental Figure S5, I-K). These results suggest that PCs deficient in CTSD are more vulnerable than those deficient in Atg7, and this vulnerability does not depend on the severity of axonal swelling.

In the cerebellar cortex of the $\mathrm{Atg} 7^{F / F}$;GRID2-Cre mice, immunoreactivity for GFAP and Ibal was increased at 2 months after birth, indicating the activation of Bergmann glias and/or astrocytes and microglial cells (Supplemental Figure S6, $\mathrm{G}-\mathrm{J})$. The somata of the PCs were delineated by surrounding activated Bergmann glias and/or astrocytes but not by activated microglial cells (Supplemental Figure S6, H and J). Furthermore, the degenerating PCs of the $\operatorname{Atg} 7^{F / F}$;GRID2-Cre mice were also negative for both TUNEL and active caspase-3 (Supplemental Figure S6, A-D). Electron microscopy showed that most of the remaining Atg7-deficient PCs with normal electron density at 2 months after birth already showed abnormal morphologic features such as irregularly shaped nuclei with small chromatin clumping, the accumulation of fragmented mitochondria in the perikarya, and tubulovesicular structures forming a spheroid in the axon initial segment (Figure 5, D and E). In such spheroids, small vesicles with or without dense cores accumulated (Figure 5F). After the PCs became electron dense, they possessed irregularly shaped nuclei with small patches of clumped chromatin and a vesiculation of the Golgi apparatus (Figure 5, G-J). Even in later stages, a synaptic connection was still preserved on the surface membranes of degenerating PCs (Figure 5K). Collectively, the morphologic features of degenerating Atg7-deficient PCs were distinct from typical apoptosis. Degenerating CTSD- and Atg7deficient PCs might share certain common morphologic features; however, massive accumulation of lysosomes and/or autophagosomes was observed only in the CTSD-deficient PCs (Supplemental Figure S2F). No difference was found in the intensity and cytoplasmic distribution pattern of the granular immunoreactivity for LAMP1 between PCs of $A t g 7^{F / F}$ and $\operatorname{Atg} 7^{F / F}$;GRID2-Cre mice (Supplemental Figure S6, $\mathrm{E}$ and $\mathrm{F})$. 


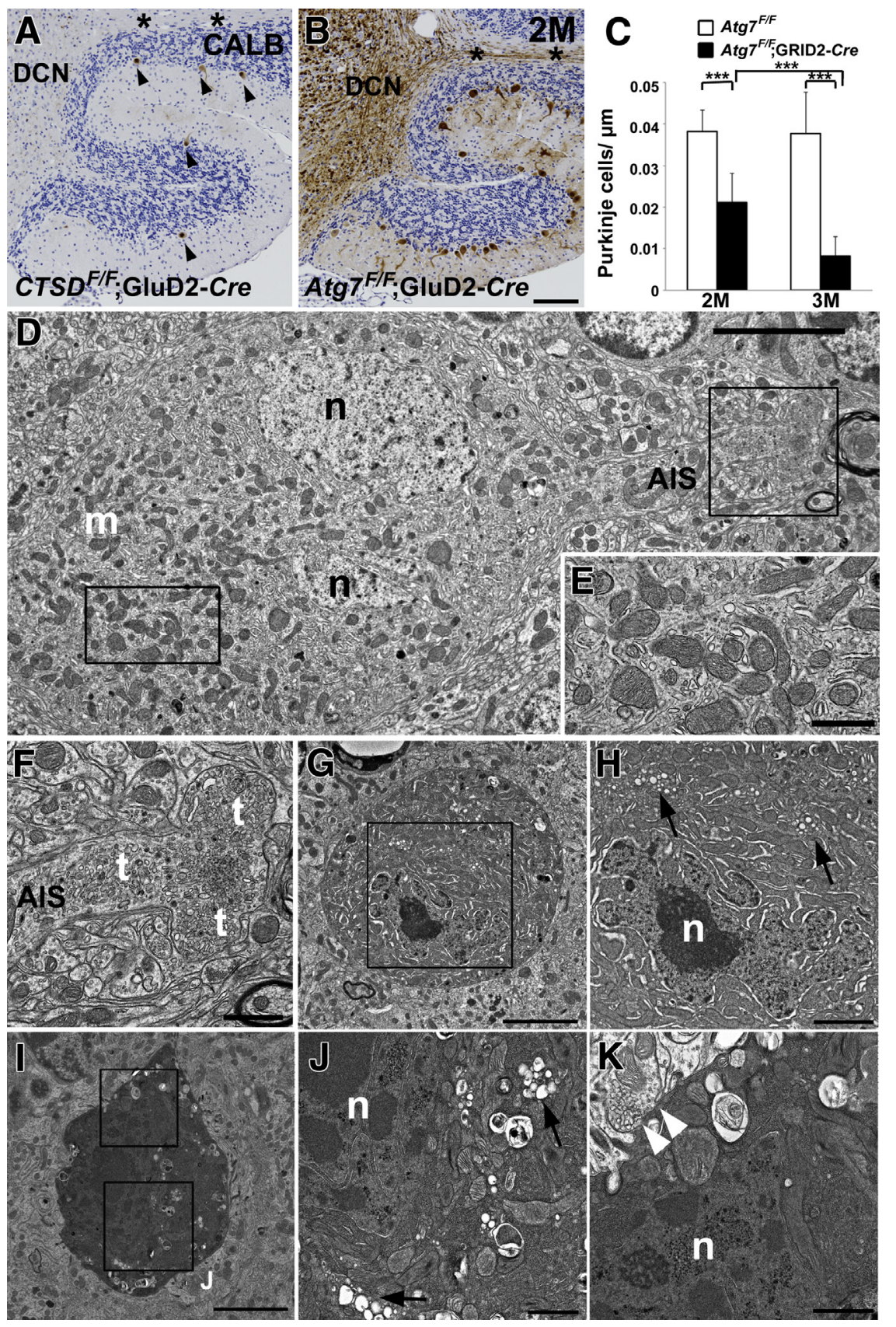

Figure $5 \quad$ A and B: Immunohistochemistry for CALB in the nodulus of the cerebellum obtained from $C T S D^{F / F}$;GRID2-Cre (A) and $A \operatorname{tg} 7^{F / F}$;GRID2-Cre (B) mice at 2M. In CTSD ${ }^{F / F}$;GRID2-Cre mice a few PCs with CALB immunoreactivity remain, but these PCs have poor dendritic immunoreactivity (arrowheads). Immunoreactivity for CALB is negative in the cerebellar white matter (asterisks) and DCN. In $A \operatorname{tg} 7^{F / F} ; G R I D 2-C r e$ mice, a considerable number of the CALB-positive PCs remain. Immunoreactivity for CALB is observed in the cerebellar white matter (asterisks). In the DCN coarse immunoreactivity for CALB is observed. C: Quantification of the surviving $P C S$ in the $A \operatorname{tg} 7^{F / F}$ and $\operatorname{Atg}^{\mathrm{F} / F}$;GRID2-Cre mice at 2M and 3M. D-K: Electron microscopy of the PCs of the $A t g 7^{F / F}$;GRID2Cre mice at 2M. The left and right boxed areas in $\mathbf{D}$ are shown at higher magnification in $\mathbf{E}$ and $\mathbf{F}$, respectively. The boxed area in $\mathbf{G}$ is shown at higher magnification in $\mathbf{H}$. The upper and lower boxed areas in I are shown at higher magnification in $\mathbf{K}$ and $\mathbf{J}$, respectively. $\mathbf{D}-\mathbf{F}$ : An Atg7-deficient $\mathrm{PC}$ that possesses $\mathrm{n}$ with small chromatin clumping and margination. Note the accumulation of fragmented $\mathrm{m}$ and $\mathrm{t}$ forming a spheroid in the perikarya $(\mathbf{E})$ and the AIS $(\mathbf{F})$, respectively. $\mathbf{G}-\mathbf{K}$ : Degenerating $\mathrm{PCs}$ with higher electron density possess irregularly shaped $\mathrm{n}$ with small patches of clumped chromatin. Arrows indicate the vesiculation of the Golgi apparatus. In earlier stages, the perinuclear space and lumen of the endoplasmic reticulum are enlarged ( $\mathbf{G}$ and $\mathbf{H})$. In later stages, a nuclear envelope remains in the degenerating $P C$ with higher electron density ( $\mathbf{J}$ and $\mathbf{K}$ ). Arrowheads in $\mathbf{K}$ indicate a synaptic connection on the degenerating PC. Data are expressed as means \pm SEM. $n=3$ slices. ${ }^{* * *} P<0.001$ (oneway analysis of variance with Tukey's post hoc test). Scale bars: $100 \mu \mathrm{m}$ (A and B); $5 \mu \mathrm{m}$ (D, G, and $\mathbf{I}) ; 2 \mu \mathrm{m}(\mathbf{H}) ; 1 \mu \mathrm{m}(\mathbf{E}, \mathbf{F}, \mathbf{J}$, and $\mathbf{K}) .2 \mathrm{M}, 2$ months; 3M, 3 months; AIS, axon initial segment; CALB, calbindin; DCN, deep cerebellar nuclei; $\mathrm{m}$, mitochondria; $\mathrm{n}$, nuclei; $\mathrm{PC}$, Purkinje cell; $\mathrm{t}$, tubulovesicular structures.

\section{Ultrastructural Comparison of Axonal Spheroids between CTSD- and Atg7-Deficient PCs}

The present study compared the ultrastructures of axonal swelling between $C T S D$ - and Atg7-deficient PCs. Four types of accumulating ultrastructural profiles were observed in the swollen axons of Atg7-deficient PCs (Supplemental Figure S7). Abnormal structures in the axonal swelling were also observed in the presynaptic terminals of Atg7deficient PCs. The first of these structures amounted to an accumulation of fibrous materials containing microtubules (Supplemental Figure S7, A and B). Immunoelectron microscopy revealed that the second was an aggregation of synaptophysin-positive small vesicles encircled by a single membrane (Supplemental Figure S7, C-E). The third type of these structures involved stacks of long and short cisternae with continuous honeycomb-like tubular structures (Supplemental Figure S7, F-K), and the fourth type amounted to an accumulation of autophagosome-type double membrane-bound structures (Supplemental Figure S7G). When stained for LC3, VGAT, and calbindin, the immunoreactivity for LC3 was negative in the swollen axons of the Atg7-deficient PCs (Supplemental Figure S7, L-O). Therefore, it seems likely that double membrane-bound 
structures would be identical to the incomplete autophagosomes described in the $\operatorname{Atg} 5^{F / F} ;$ Pcp2-Cre mice. ${ }^{19}$

\section{Discussion}

The processes of autophagy and lysosomal proteolysis have crucial roles in the maintenance of neuronal homeostasis, and increasing evidence has shown that dysfunctional lysosomal proteolysis and autophagy systems result in various neurodegenerative diseases, including Alzheimer and Parkinson diseases. ${ }^{2,35}$ Moreover, several rare inherited neurodegenerative disorders that are due to mutations in the genes that encode Atg5 or several lysosomal proteinases have been discovered. $^{8-11,36,37}$ Because ataxia is known to be the prominent phenotype in cases of neurodegenerative disorders marked by mutations of human CTSD and ATG5 genes, ${ }^{9,20}$ it is important to diagram the mechanisms for the neurodegeneration of PCs using mouse models of these disorders. As for impairment of autophagy, PCs lacking Atg5 or Atg7 are known to undergo cell-autonomous neurodegeneration characterized by massive levels of axonal swelling. ${ }^{18,19}$ However, the fate of the CTSD-deficient PCs is not yet well understood because conventional $C T S D^{-1-}$ mice die at around P26 $\pm 1,3,13$ when PCs remain in the cerebellum. Therefore, we established a novel strain of conditional $\mathrm{KO}$ mice for $C T S D$ and generated $C T S D^{F / F}$;GRID2-Cre, where $C T S D$ has been selectively deleted from the PCs. Immunohistochemical and ultrastructural analyses confirmed that these $C T S D$-deficient PCs exhibited typical NCL pathology, which has been described in conventional $C T S D^{-1-}$ mice. ${ }^{3,5}$ Morphologic analyses revealed that CTSD-deficient PCs started to degenerate at about 4 weeks after birth and had largely disappeared at around 2 months, which led to an ataxic phenotype of the $C T S D^{F / F}$;GRID2-Cre mice as evidenced by with their poor rotarod performance. Impairment of motor skills may be associated with their mild weight loss, which is also one of the phenotypes of several strains of mutant mice with ataxia. ${ }^{38}$

In conventional $C T S D^{-1-}$ mice, apoptosis of the photoreceptor cells is abundant, whereas neurons in the thalamus and the inner nuclear layer of the retina exhibit necrotic cell death, which is accompanied by a massive activation of astrocytes and microglial cells. ${ }^{4,6}$ Our pharmacologic evidence has revealed that microglial cells, which encircle neurons and release nitric oxide, contribute to massive levels of neuronal death in these regions of conventional $C T S D^{-1-}$ mice. ${ }^{6}$ By contrast, in the cerebellar cortex of $C T S D^{F / F}$;GRID2-Cre mice, electron microscopy and immunohistochemistry for Iba1 has shown that microglial cells were only transiently activated and did not encircle degenerating PCs. Thus, we assumed that microglial cells were activated only after the cellular degeneration of CTSDdeficient PCs. Although we cannot exclude the possibility that activated Bergmann glias and/or astrocytes positively contribute to the dying process of CTSD-deficient PCs, the results of the present study strongly suggest the cellautonomous degeneration of CTSD-deficient PCs.

Next, we compared the neurodegenerative processes of the CTSD- and Atg7-deficient PCs by generating $A t g 7^{F / F}$;GRID2Cre mice. By immunohistochemistry for CTSD, Atg7, and p62/SQSTM1, deletion of CTSD in lysosomes in PCs of the $C T S D^{F / F}$;GRID2-Cre and impairment of autophagy in PCs of the $A \operatorname{tg} 7^{F / F}$;GRID2-Cre mice were confirmed to be completed at least at P14. Most PCs of the $A \operatorname{tg} 7^{F / F}$;GRID2-Cre mice had disappeared within 3 months of birth, whereas degeneration of the CTSD-deficient PCs proceeded much more rapidly and were completely lost within 2 months, indicating that $C T S D$ deficient PCs are more vulnerable than those deficient in Atg7. We hypothesized that the rapid degeneration of CTSDdeficient PCs could be attributed to the massive accumulation of autophagosomes and GRODs in the soma. As described previously, ${ }^{5}$ the GRODs themselves were often enwrapped by autophagosomes in CTSD-deficient PCs, indicating that GRODs containing undigested materials have some cytotoxic effects. Thus far, the mitochondrial subunit $\mathrm{c}$ in GRODs is considered to be among the in vivo substrates for CTSD, 3,39 most of which are yet to be identified. Further studies concerning the molecular mechanisms of the sequestration of GRODs by autophagy and specific endogenous substrates for CTSD in neurons would be important to promote a better understanding of the effect that $C T S D$ deficiency exerts on PCs.

The types of cell death in degenerating CTSD- and Atg7deficient PCs were analyzed ultrastructurally and histochemically. These degenerating PCs showed no typical apoptotic features. Our previous genetic study on a mouse model for neonatal hypoxia-ischemia injury has shown that multiple cell death pathways, including both apoptosis and autophagic cell death, participate in the dying process of ipsilateral hippocampal neurons. ${ }^{26}$ Recent evidence has begun to indicate that necroptosis and ferroptosis also contribute to the pathogenesis of neurodegenerative disorders. ${ }^{40,41}$ Likewise, multiple modes of cell death might participate in the dying process of CTSD-deficient PCs. Further pharmacologic and genetic analyses are necessary to determine the major types of cell death pathways for PCs, which would contribute to a novel therapeutic approach.

The common pathogenic event in the cerebellum between $C T S D^{F / F}$;GRID2-Cre and $\mathrm{Atg} 7^{F / F}$;GRID2-Cre mice was the swelling of the axons, which occurred in close proximity to the axon terminals of CTSD- and Atg7-deficient PCs, indicating that both CTSD deficiency in lysosomes and impairment of autophagy induce axonal swelling in a cellautonomous manner. The swelling of the axons and presynaptic terminals of the Atg7-deficient PCs became progressively more severe compared with those of the CTSD-deficient PCs. These results suggest that vulnerability of the CTSD-deficient PCs, which underwent degeneration faster than Atg7-deficient PCs, does not depend on the severity of axonal swelling. Evidence showing that a gradual accumulation of GRODs occurred only in the 
neurosoma, but never in the axons of the CTSD-deficient PCs, further strengthened our theory that pathologic changes in the neurosoma of CTSD-deficient PCs, particularly with regard to the accumulation of GRODs, played a critical role in the rapid degeneration of those PCs.

The present study demonstrated several common ultrastructural changes in the swollen axons of CTSD- and Atg7-deficient PCs in addition to those found only in Atg7deficient PCs. In both CTSD- and Atg7-deficient PCs, double membrane-bound structures were commonly observed in the swelling of axons and presynaptic terminals. Immunohistochemistry showed that these axonal swellings were intensely positive for LC3 in CTSD-deficient PCs but not in Atg7-deficient PCs, suggesting that the double membrane-bound structures in CTSD-deficient PCs corresponded to autophagosomes and that those in Atg7-deficient PCs could possibly be related to the autophagy precursors found in $\mathrm{Atg} 5^{F / F} ;$ Pcp2-Cre mice. ${ }^{19}$ Other common ultrastructural changes in the swollen axons included the massive accumulation of honeycomb-like tubular structures and/or the stacks of cisternal membranes. We also noticed that the convoluted double-membrane whorls and abnormal filaments described in the $\mathrm{Atg} 7^{F / F} ; \mathrm{Pcp} 2-\mathrm{Cre}$ mice ${ }^{18}$ were morphologically identical to the stacks of long and short cisternae observed in the PCs of $\operatorname{Atg} 7^{F / F}$;GRID2-Cre mice. Note that these honeycomb-like tubular structures and stacks of cisternal membranes seemed to weave together. The honeycomb-like tubulovacuolar structures, which are also present in the axons of normal PCs, are derived from smooth endoplasmic reticulum, ${ }^{33}$ which indicates an important role for the autophagy-lysosomal pathway in the clearance of such membrane structures. The morphologic changes that appeared only in the swollen axons of the Atg7-deficient PCs were the accumulation of fibrous materials containing microtubules and the single membrane-bound aggregations of synaptophysin-positive small vesicles, both of which were not described previously. ${ }^{18,19}$ It seems apparent that basal autophagy in axons was also important for the constitutive degradation of cytoskeletal proteins and synaptic vesicles by macroautophagy. In contrast to the well-established evidence on the critical roles for autophagy in the maintenance of axonal homeostasis both in vivo and in vitro, ${ }^{42-44}$ the precise reason for axonal swelling in CTSD-deficient PCs remains unclear, because there are no typical lysosomes along axons. ${ }^{45}$ Further investigation is necessary to establish the precise relations between the blockage of the axonal transport and the defects of lysosomal proteinases in the soma.

\section{Conclusions}

Our study provides genetic evidence for the indispensable role of CTSD and Atg7 in the survival of PCs and the maintenance of axonal homeostasis. This report provides comparative analyses of the neuropathology of PC-specific
CTSD- and Atg7-deficient mice that should promote the elucidation of the specific pathogenesis of rare neurodegenerative diseases that are associated with CTSD and Atg5 mutations and other neurodegenerative disorders, because cell death and axonal swelling, which are hallmarks of axonal dystrophy, are observed in many central nervous system disorders. ${ }^{5,46}$ The crossing of various tissue- or cell-type-specific Cre mice with the CTSD- and Atg7conditional $\mathrm{KO}$ mice will contribute to further insight into the neuronal and/or glial cell- or brain-region-specific pathogenesis of related neurodegenerative disorders.

\section{Acknowledgments}

We thank Yoshimitsu Kobayashi, Yoko Furuta, Hosung Lee, and Mina Igari for their technical assistance.

\section{Supplemental Data}

Supplemental material for this article can be found at http://dx.doi.org/10.1016/j.ajpath.2017.02.020.

\section{References}

1. Uchiyama Y, Waguri S, Sato N, Watanabe T, Ishido K, Kominami E: Cell and tissue distribution of lysosomal cysteine proteinases, cathepsins B, H, and L, and their biological roles. Acta Histochem Cytochem 1994, 27:351-372

2. Uchiyama Y, Shibata M, Koike M, Yoshimura K, Sasaki M: Autophagy-physiology and pathophysiology. Histochem Cell Biol 2008, 129:407-420

3. Koike M, Nakanishi H, Saftig P, Ezaki J, Isahara K, Ohsawa Y, Schulz-Schaeffer W, Watanabe T, Waguri S, Kametaka S, Shibata M, Yamamoto K, Kominami E, Peters C, von Figura K, Uchiyama Y: Cathepsin D deficiency induces lysosomal storage with ceroid lipofuscin in mouse CNS neurons. J Neurosci 2000, 20:6898-6906

4. Koike M, Shibata M, Ohsawa Y, Nakanishi H, Koga T, Kametaka S, Waguri S, Momoi T, Kominami E, Peters C, Figura K, Saftig P, Uchiyama Y: Involvement of two different cell death pathways in retinal atrophy of cathepsin D-deficient mice. Mol Cell Neurosci 2003, 22:146-161

5. Koike M, Shibata M, Waguri S, Yoshimura K, Tanida I, Kominami E, Gotow T, Peters C, von Figura K, Mizushima N, Saftig P, Uchiyama Y: Participation of autophagy in storage of lysosomes in neurons from mouse models of neuronal ceroid-lipofuscinoses (Batten disease). Am J Pathol 2005, 167:1713-1728

6. Nakanishi H, Zhang J, Koike M, Nishioku T, Okamoto Y Kominami E, von Figura K, Peters C, Yamamoto K, Saftig P, Uchiyama Y: Involvement of nitric oxide released from microgliamacrophages in pathological changes of cathepsin D-deficient mice. J Neurosci 2001, 21:7526-7533

7. Haltia M: The neuronal ceroid-lipofuscinoses. J Neuropathol Exp Neurol 2003, 62:1-13

8. Fritchie K, Siintola E, Armao D, Lehesjoki AE, Marino T, Powell C, Tennison M, Booker JM, Koch S, Partanen S, Suzuki K, Tyynela J, Thorne LB: Novel mutation and the first prenatal screening of cathepsin D deficiency (CLN10). Acta Neuropathol 2009, 117: 201-208

9. Hersheson J, Burke D, Clayton R, Anderson G, Jacques TS, Mills P, Wood NW, Gissen P, Clayton P, Fearnley J, Mole SE, Houlden H: 
Cathepsin D deficiency causes juvenile-onset ataxia and distinctive muscle pathology. Neurology 2014, 83:1873-1875

10. Siintola E, Partanen S, Stromme P, Haapanen A, Haltia M, Maehlen J, Lehesjoki AE, Tyynela J: Cathepsin D deficiency underlies congenital human neuronal ceroid-lipofuscinosis. Brain 2006, 129:1438-1445

11. Steinfeld R, Reinhardt K, Schreiber K, Hillebrand M, Kraetzner R, Bruck W, Saftig P, Gartner J: Cathepsin d deficiency is associated with a human neurodegenerative disorder. Am J Hum Genet 2006, 78 : 988-998

12. Shacka JJ, Klocke BJ, Young C, Shibata M, Olney JW, Uchiyama Y, Saftig P, Roth KA: Cathepsin D deficiency induces persistent neurodegeneration in the absence of Bax-dependent apoptosis. J Neurosci 2007, 27:2081-2090

13. Saftig P, Hetman M, Schmahl W, Weber K, Heine L, Mossmann H, Koster A, Hess B, Evers M, von Figura K: Mice deficient for the lysosomal proteinase cathepsin D exhibit progressive atrophy of the intestinal mucosa and profound destruction of lymphoid cells. EMBO J $1995,14: 3599-3608$

14. Koike M, Shibata M, Ezaki J, Peters C, Saftig P, Kominami E, Uchiyama Y: Differences in expression patterns of cathepsin C/dipeptidyl peptidase I in normal, pathological and aged mouse central nervous system. Eur J Neurosci 2013, 37:816-830

15. Mehanna S, Suzuki C, Shibata M, Sunabori T, Imanaka T, Araki K, Yamamura K, Uchiyama Y, Ohmuraya M: Cathepsin D in pancreatic acinar cells is implicated in cathepsin B and L degradation, but not in autophagic activity. Biochem Biophys Res Commun 2016, 469: 405-411

16. Yamamoto-Nonaka K, Koike M, Asanuma K, Takagi M, Oliva Trejo JA, Seki T, Hidaka T, Ichimura K, Sakai T, Tada N, Ueno T, Uchiyama Y, Tomino Y: Cathepsin D in podocytes is important in the pathogenesis of proteinuria and CKD. J Am Soc Nephrol 2016, 27 : 2685-2700

17. Yamasaki M, Miyazaki T, Azechi H, Abe M, Natsume R, Hagiwara T, Aiba A, Mishina M, Sakimura K, Watanabe M: Glutamate receptor delta2 is essential for input pathway-dependent regulation of synaptic AMPAR contents in cerebellar Purkinje cells. J Neurosci 2011, 31: 3362-3374

18. Komatsu M, Wang QJ, Holstein GR, Friedrich VL Jr, Iwata J, Kominami E, Chait BT, Tanaka K, Yue Z: Essential role for autophagy protein Atg7 in the maintenance of axonal homeostasis and the prevention of axonal degeneration. Proc Natl Acad Sci U S A 2007, 104: 14489-14494

19. Nishiyama J, Miura E, Mizushima N, Watanabe M, Yuzaki M: Aberrant membranes and double-membrane structures accumulate in the axons of Atg5-null Purkinje cells before neuronal death. Autophagy 2007, 3:591-596

20. Kim M, Sandford E, Gatica D, Qiu Y, Liu X, Zheng Y, Schulman BA, Xu J, Semple I, Ro SH, Kim B, Mavioglu RN, Tolun A, Jipa A, Takats S, Karpati M, Li JZ, Yapici Z, Juhasz G, Lee JH, Klionsky DJ, Burmeister M: Mutation in ATG5 reduces autophagy and leads to ataxia with developmental delay. Elife 2016, 5:e12245

21. Komatsu M, Waguri S, Ueno T, Iwata J, Murata S, Tanida I, Ezaki J, Mizushima N, Ohsumi Y, Uchiyama Y, Kominami E, Tanaka K, Chiba T: Impairment of starvation-induced and constitutive autophagy in Atg7-deficient mice. J Cell Biol 2005, 169:425-434

22. Committee for the Update of the Guide for the Care and Use of Laboratory Animals; National Research Council: Guide for the Care and Use of Laboratory Animals. ed 8. Washington, DC, National Academies Press, 2011

23. Eggan K, Akutsu H, Loring J, Jackson-Grusby L, Klemm M, Rideout WM III, Yanagimachi R, Jaenisch R: Hybrid vigor, fetal overgrowth, and viability of mice derived by nuclear cloning and tetraploid embryo complementation. Proc Natl Acad Sci U S A 2001, 98:6209-6214

24. Sakai K, Miyazaki J: A transgenic mouse line that retains Cre recombinase activity in mature oocytes irrespective of the cre transgene transmission. Biochem Biophys Res Commun 1997, 237 : 318-324

25. Kominami E, Ezaki J, Muno D, Ishido K, Ueno T, Wolfe LS: Specific storage of subunit c of mitochondrial ATP synthase in lysosomes of neuronal ceroid lipofuscinosis (Batten's disease). J Biochem 1992, 111:278-282

26. Koike M, Shibata M, Tadakoshi M, Gotoh K, Komatsu M, Waguri S, Kawahara N, Kuida K, Nagata S, Kominami E, Tanaka K, Uchiyama Y: Inhibition of autophagy prevents hippocampal pyramidal neuron death after hypoxic-ischemic injury. Am J Pathol 2008, 172: 454-469

27. Tashiro $Y$, Urushitani $M$, Inoue $H$, Koike $M$, Uchiyama $Y$, Komatsu M, Tanaka K, Yamazaki M, Abe M, Misawa H, Sakimura K, Ito H, Takahashi R: Motor neuron-specific disruption of proteasomes, but not autophagy, replicates amyotrophic lateral sclerosis. J Biol Chem 2012, 287:42984-42994

28. Koike M, Tanida I, Nanao $T$, Tada N, Iwata J, Ueno $T$, Kominami E, Uchiyama Y: Enrichment of GABARAP relative to LC3 in the axonal initial segments of neurons. PLoS One 2013, 8: e63568

29. Sato S, Koike M, Funayama M, Ezaki J, Fukuda T, Ueno T, Uchiyama Y, Hattori N: Lysosomal storage of subunit c of mitochondrial ATP synthase in brain-specific Atp13a2-deficient mice. Am J Pathol 2016, 186:3074-3082

30. Shibata M, Koike M, Waguri S, Zhang G, Koga T, Uchiyama Y: Cathepsin D is specifically inhibited by deoxyribonucleic acids. FEBS Lett 2002, 517:281-284

31. Ebels EJ, Blaauw EH: Honeycomb-like intra-axonal tubular structures in irradiated rat cerebella. Acta Neuropathol 1968, 11: $262-265$

32. Hirano A, Sax DS, Zimmerman HM: The fine structure of the cerebella of jimpy mice and their "normal" litter mates. J Neuropathol Exp Neurol 1969, 28:388-400

33. Sotelo C, Palay SL: Altered axons and axon terminals in the lateral vestibular nucleus of the rat. Possible example of axonal remodeling. Lab Invest 1971, 25:653-671

34. Komatsu M, Waguri S, Koike M, Sou YS, Ueno T, Hara T, Mizushima N, Iwata J, Ezaki J, Murata S, Hamazaki J, Nishito Y, Iemura $S$, Natsume $T$, Yanagawa $T$, Uwayama J, Warabi E, Yoshida H, Ishii T, Kobayashi A, Yamamoto M, Yue Z, Uchiyama Y, Kominami E, Tanaka K: Homeostatic levels of p62 control cytoplasmic inclusion body formation in autophagy-deficient mice. Cell 2007, 131:1149-1163

35. Nixon RA: The role of autophagy in neurodegenerative disease. Nat Med 2013, 19:983-997

36. Sleat DE, Donnelly RJ, Lackland H, Liu CG, Sohar I, Pullarkat RK, Lobel P: Association of mutations in a lysosomal protein with classical late-infantile neuronal ceroid lipofuscinosis. Science 1997, 277: $1802-1805$

37. Smith KR, Dahl HH, Canafoglia L, Andermann E, Damiano J, Morbin M, Bruni AC, Giaccone G, Cossette P, Saftig P, Grotzinger J, Schwake M, Andermann F, Staropoli JF, Sims KB, Mole SE, Franceschetti S, Alexander NA, Cooper JD, Chapman HA, Carpenter S, Berkovic SF, Bahlo M: Cathepsin F mutations cause Type B Kufs disease, an adult-onset neuronal ceroid lipofuscinosis. Hum Mol Genet 2013, 22: $1417-1423$

38. Cendelin J: From mice to men: lessons from mutant ataxic mice. Cerebellum Ataxias 2014, 1:4

39. Ezaki J, Takeda-Ezaki M, Kominami E: Tripeptidyl peptidase I, the late infantile neuronal ceroid lipofuscinosis gene product, initiates the lysosomal degradation of subunit c of ATP synthase. J Biochem 2000, 128:509-516

40. Chen L, Hambright WS, Na R, Ran Q: Ablation of the ferroptosis inhibitor glutathione peroxidase 4 in neurons results in rapid motor neuron degeneration and paralysis. J Biol Chem 2015, 290: 28097-28106 
41. Fayaz SM, Suvanish Kumar VS, Rajanikant GK: Necroptosis: who knew there were so many interesting ways to die? CNS Neurol Disord Drug Targets 2014, 13:42-51

42. Hollenbeck PJ: Products of endocytosis and autophagy are retrieved from axons by regulated retrograde organelle transport. J Cell Biol 1993, 121:305-315

43. Katsumata K, Nishiyama J, Inoue T, Mizushima N, Takeda J, Yuzaki M: Dynein- and activity-dependent retrograde transport of autophagosomes in neuronal axons. Autophagy 2010, 6:378-385
44. Maday S, Wallace KE, Holzbaur EL: Autophagosomes initiate distally and mature during transport toward the cell soma in primary neurons. J Cell Biol 2012, 196:407-417

45. Broadwell RD, Cataldo AM: The neuronal endoplasmic reticulum: its cytochemistry and contribution to the endomembrane system. II. Axons and terminals. J Comp Neurol 1984, 230: $231-248$

46. Coleman M: Axon degeneration mechanisms: commonality amid diversity. Nat Rev Neurosci 2005, 6:889-898 